\title{
ROLE OF CHLORIDE IONS IN RELATION TO COPPER CORROSION AND INHIBITION
}

\author{
S. M. Mayanna and T. H. V. SetTy* \\ (Department of Chemistry, Central College, Bangalore University, Bangalore 56C001) \\ MS received 18 February 1974; after revision 12 July 1974 \\ (Communicated by Prof. M. Santappa, F.A.Sc.)
}

\begin{abstract}
Corrosion rates of copper single crystal faces are determined in stirred $0.1 \mathrm{~N}$ sulphuric acid with various chloride ion concentrations. A mechanism is proposed to explain the variation of corrosion rate with $\mathrm{Cl}^{-}$ion concentration. Up to $7.5 \times 10^{-3} \mathrm{M} \mathrm{Cl}^{-}$ions, the stabilities of the crystal faces are in the order $(111)>(100)>(110)$ but this order is changed to $(110)>(100)>(111)$ in presence of $10^{-2} \mathrm{M} \mathrm{Cl}^{-}$ions. The corrosion potentials of the crystal faces are less noble at all concentra. tions of $\mathrm{Cl}^{-}$ions and $\mathrm{Cl}^{-}$ion acts as a cathodic inhibitor. There is no significant orientation effect on the kinetics of dissolution of copper.
\end{abstract}

\section{INTRODUCTION}

Corrosion promotion or inhibition by anions is said to depend on the solubility product of the reaction product, ${ }^{1}$ adsorption, ${ }^{2}$ ion size and charge, ${ }^{3}$ ion deformability, ${ }^{4}$ electrostatic field set up by the negative charge of the anion on the adsorption site ${ }^{5}$ and the concentration of anions ${ }^{6}$. The kinetics of corrosion of copper ${ }^{7}$ in acidic copper sulphate solution containing chloride ions is influenced by the precipitation of cuprous chloride on the metal surface. Bertocci ${ }^{8}$ has studied the kinetics of anodic dissolution of copper single crystal faces in chloride solutions and concluded that cuprous ions have a prominent role in copper corrosion process. It is known that many properties of metallic single crystals, including catalytic ${ }^{9}$ and adsorption characteristics $^{10}$ are anisotropic. Although it is impossible to predict in advance the crystal face which under a given set of conditions will be the most resistant to corrosion, a knowledge of the principles and experimental facts bearing on the effect of crystal face is helpful in obtaining a better

\footnotetext{
* Deceased.
} 
understanding of the mechanism of corrosion. Most of the earlier investigations have been done using polycrystalline copper, in solutions containing cuprous or cupric ions along with high concentration of chloride ions. In this paper the results of some experiments showing the influence of chloride ions on the corrosion of copper single crystal faces in dilute sulphuric acid free from cuprous or cupric ions are given.

\section{Materials AND Methods}

Solutions were prepared from freshly distilled AR sulphuric acid and recrystallised AR potassium chloride using conductivity water. 99.999\% copper (110), (100) and (111) crystal faces with dislocation density of the order of $10^{5} / \mathrm{cm}^{2}$ were fixed in tygon tubing, exposing only the desired faces. These crystal faces were mechanically polished on $4 / 0$ emery paper using ethyl alcohol as lubricant and then electropolished in 1: 1 orthophosphoric acid $^{11}$ at a cell potential of $1 \cdot 2 \mathrm{~V}$ for 30 minutes. The dissolution was carried out in a three-necked R.B. flask of $100 \mathrm{ml}$ capacity containing aerated stirred $0 \cdot 1 \mathrm{~N}$ sulphuric acid with desired amount of potassium chloride. After dissolution, the crystal was taken out, washed with triple distilled water and dried with alcohol. The crystal surface was observed under a metallurgical microscope and microphotographs were taken whenever desired. The dissolved copper in the solution was estimated by carbamate method using a Hilger colorimeter. The corrosion potentials were measured at regular intervals with respect to a $\mathrm{Hg} / \mathrm{Hg}_{2} \mathrm{SO}_{4}$ reference electrode using dc VTVM with an accuracy of $\pm 1 \mathrm{mV}$. A more detailed description has been given in a previous paper. ${ }^{12}$

\section{RESULTS}

\section{Corrosion Rates}

Copper single crystal (110), (100) and (111) faces were dissolved at $30^{\circ} \mathrm{C}$ and the corrosion rates $\left(\mathrm{mg} / \mathrm{cm}^{2} / \mathrm{hr}\right)$ were calculated. The corrosion rates of the crystal faces varied with the increase of $\mathrm{Cl}^{-}$ion concentration. However, for a given concentration of $\mathrm{Cl}^{-}$ions, different crystal faces had slightly different corrosion rates. The corrosion rates increased slightly when the concentration of $\mathrm{Cl}^{-}$ions was increased from $10^{-8}$ to $10^{-3} \mathrm{M}$. The corrosion rate passed through maximum to minimum value when the concentration of $\mathrm{Cl}^{-}$ions was inbetween $10^{-3} M$ and $10^{-2} M$ (figure 1). The (111) face had a corrosion rate about $23 \%$ less than that of the (110) face in presence of $10^{-3} \mathrm{M} \mathrm{Cl}^{-}$ions. However, at $7 \cdot 5 \times 10^{-3} \mathrm{M} \mathrm{Cl}^{-}$ions, the (111) 


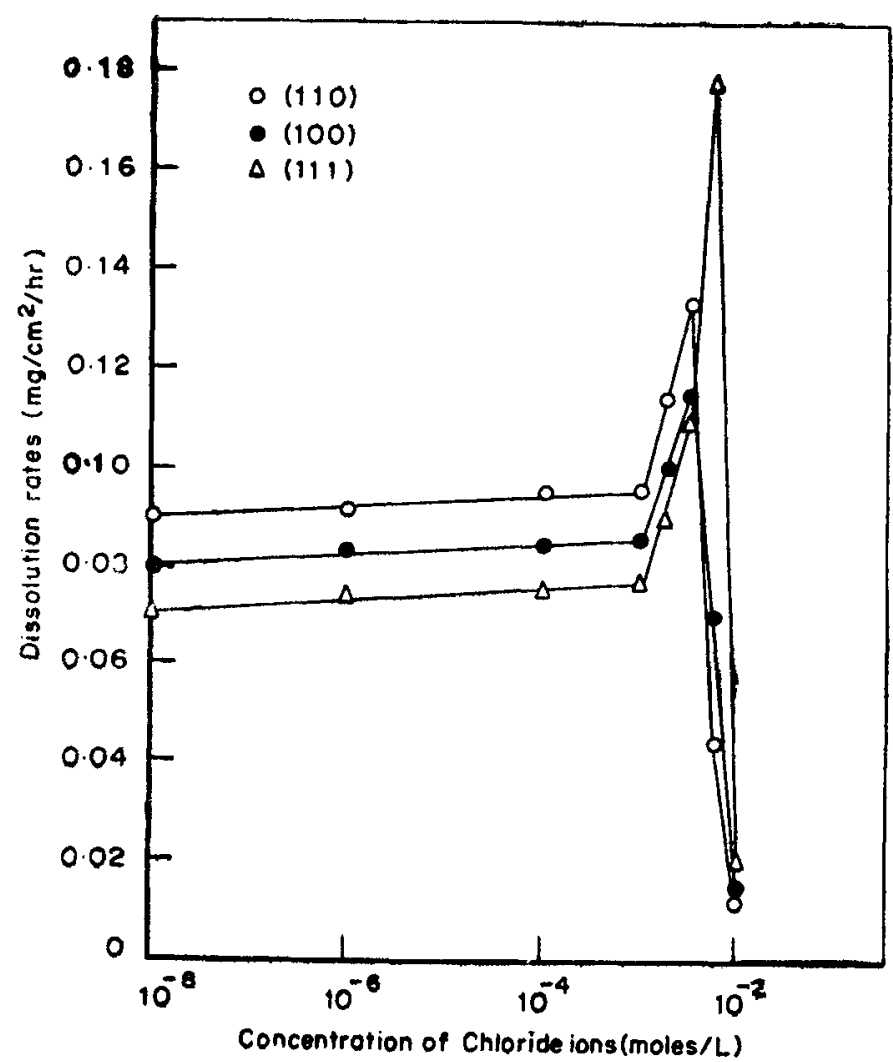

Figure 1. Influence of concentration $\left(C\right.$, mole/l) of $\mathrm{Cl}^{\text {w }}$ ions on the dissolution rates of copper single crystal faces at $30^{\circ} \mathrm{C}$.

face had a rate about $300 \%$ higher than that of the (110) face. Up to $5 \times 10^{-3}$ $M \mathrm{Cl}^{-}$ions the corrosion rates of crystal faces were in the order $(110)>(100)$ $>$ (111) and this order changed to $(111)>(100)>(110)$ when the concentration of $\mathrm{Cl}^{-}$ions was greater than $5 \times 10^{-3} \mathrm{M}$.

The corrosion rates of $(110),(100)$ and (111) faces in aerated stirred $0.1 N$ sulphuric acid were reported earlier. ${ }^{12}$ These corrosion rates were comparatively higher than those with $10^{-8} \mathrm{M} \mathrm{Cl}^{-}$ions. Copper (110) face was dissolved at different time intervals with and without $10^{-2} \mathrm{M} \mathrm{Cl}^{-}$ions. Weight loss as a function of time is given in figure 2, for the corrosion of copper (110) face in $0.1 \mathrm{~N}$ sulphuric acid and $0.1 \mathrm{~N}$ sulphuric acid containing $10^{-2} M \mathrm{Cl}^{-}$ions. The crystal face dissolved with a steady rate in sulphuric acid but it passivated within $20 \mathrm{~min}$. in presence of $10^{-2} \mathrm{M} \mathrm{Cl}^{-}$ions.

The corrosion rates were also determined at $40^{\circ}$ and $50^{\circ} \mathrm{C}$ in presence of $10^{-2} \mathrm{M} \mathrm{Cl}^{-}$ions, in order to evaluate qualitatively energy and entropy 


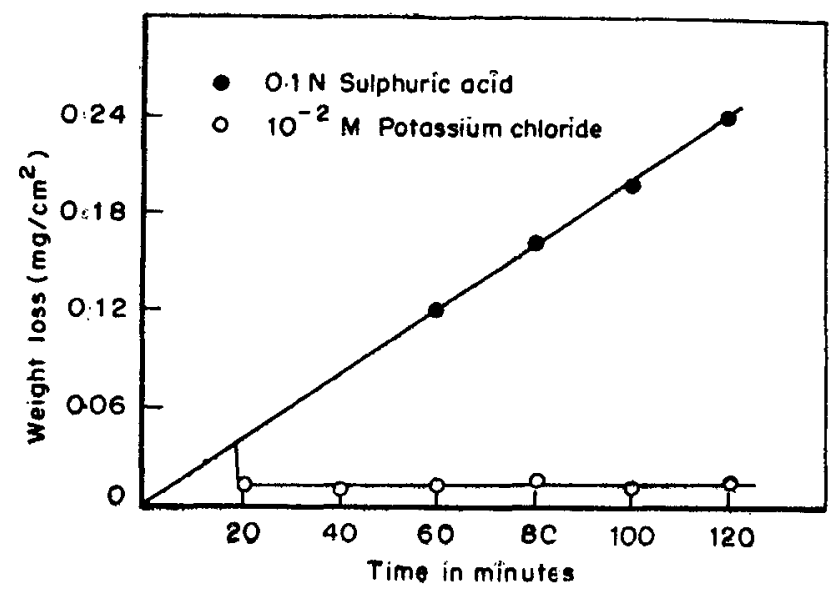

Figure 2. Variation of weight loss of copper (110) face with time in $0.1 \mathrm{~N}$ sulphuric acid and $0.1 \mathrm{~N}$ sulphuric acid containing $10^{-2} \mathrm{M} \mathrm{Cl}^{-}$ions.

of activation for the corrosion process in a solution with maximum inhibition by chloride ions. Data for the corrosion rates in $0.1 \mathrm{~N}$ sulphuric acid containing $10^{-2} \mathrm{M} \mathrm{Cl}^{-}$ions at different temperatures are summarized in table 1 . Activation energy for the corrosion process of each crystal face was evaluated by plotting log. corrosion rate against $1 / T(T$, the temperature in deg. kelvin). Entropy of activation was calculated using the equation ${ }^{13}$

$$
K=\frac{k T}{h} \exp \left(\Delta S^{+} / R\right) \quad \exp \left(\triangle H^{+} / R T\right)
$$

where $K, \triangle S^{+}$and $\triangle H^{*}$ were the corrosion rates, entropy and enthalpy of activation respectively. Entropy and energy of activation for different crystal faces were in the order $(110)>(100)>$ (111) (table 2).

The $\%$ inhibitor efficiencies were calculated as follows:

$$
\% \text { inhibition }=\left(R_{0}-R / R_{0}\right) \times 100
$$

where $R_{0}$ and $R$ were the corrosion rates without and with $\mathrm{Cl}^{-}$ions. The $\%$ inhibitor efficiency decreased gradually up to $10^{-3} \mathrm{M} \mathrm{Cl}^{-}$ions and then it began to decrease rapidly when the concentration of $\mathrm{Cl}^{-}$ions was inbetween $10^{-3} M$ and $7.5 \times 10^{-3} M$. However, the \% inhibitor efficiency was very high in presence of $10^{-2} M \mathrm{Cl}^{-}$ions. $\mathrm{Up}$ to $7.5 \times 10^{-3} \mathrm{M} \mathrm{Cl}^{-}$ions, the $\%$ inhibitor efficiencies of different crystal faces were in the order (111) $>(100)>(110)$ but in presence of $10^{-2} \mathrm{M} \mathrm{Cl}^{-}$ions, this order changed to $(110)>(100)>(111)$. The dependence of $\%$ inhibitor efficiency on chloride ion concentration is given in table 3 . 
Table 1. Corrosion rates of different crystal faces at various temperatures in presence of $10^{-2} \mathrm{M} \mathrm{Cl}^{-}$ions

\begin{tabular}{rcccc}
\hline Temperature & $(110)$ & $(100)$ & $(111)$ \\
\hline $30^{\circ} \mathrm{C}$ & $\ldots$ & 0.01235 & 0.01550 & 0.02030 \\
$40^{\circ} \mathrm{C}$ & $\ldots$ & 0.01820 & 0.02187 & 0.02761 \\
$50^{\circ} \mathrm{C}$ & $\ldots$ & 0.02643 & 0.03021 & 003682 \\
\hline
\end{tabular}

Table 2. Energy and entropy of activation in presence of $10^{-2} \mathrm{M} \mathrm{Cl}^{-}$ions

\begin{tabular}{|c|c|c|c|}
\hline & (110) & (100) & (111) \\
\hline$E_{\mathrm{g}}$ (cal/g.atom) & 7500 & 6500 & 5800 \\
\hline$\Delta S^{\neq}(\mathrm{e}, \mathrm{u})$. & $-42 \cdot 56$ & $-45 \cdot 43$ & $-47 \cdot 18$ \\
\hline $\begin{array}{c}\text { Table 3. } \% \text { inhibitor } \\
\begin{array}{c}\text { Concentration } \\
\text { of } \mathrm{Cl}^{-} \text {ions } \\
M\end{array}\end{array}$ & (110) & $(100)$ & (111) \\
\hline $10^{-8} \quad$. & $21 \cdot 74$ & $33 \cdot 34$ & $45 \cdot 31$ \\
\hline $10^{-8} \quad$. & $20 \cdot 86$ & $30 \cdot 83$ & $42 \cdot 97$ \\
\hline $10^{-4} \quad$. & $17 \cdot 39$ & $30 \cdot 0$ & $41 \cdot 41$ \\
\hline $10^{-3} \quad$. & $16 \cdot 52$ & $28 \cdot 33$ & $40 \cdot 62$ \\
\hline $2 \cdot 5 \times 10^{-3} \quad$ & $00 \cdot 86$ & $16 \cdot 66$ & $29 \cdot 69$ \\
\hline $5.0 \times 10^{-3}$ & $-16 \cdot 52$ & $4 \cdot 16$ & $14 \cdot 06$ \\
\hline $7 \cdot 5 \times 10^{-3}$ & $61 \cdot 89$ & $41 \cdot 67$ & $-39 \cdot 06$ \\
\hline $10^{-2} \ldots$ & $89 \cdot 56$ & $87 \cdot 50$ & $84 \cdot 37$ \\
\hline
\end{tabular}




\section{Topography}

The surface of all the crystal faces appeared bright with occasional pits after one hour dissolution at all temperatures and also at all concentrations of $\mathrm{Cl}^{-}$ions. On prolonged dissolution characteristic each figures were not noticed on (110), (100) and (111) crystal faces unlike in dilute sulphuric acid. ${ }^{12}$

\section{Corrosion Potentials}

Corrosion potentials were recorded during the dissolution of copper single crystal faces. Corrosion potentials as a function of time are given in figure 3 , at two different concentrations $\left(10^{-8} M\right.$ and $\left.10^{-2} M\right)$ of $\mathrm{Cl}^{-}$ions.

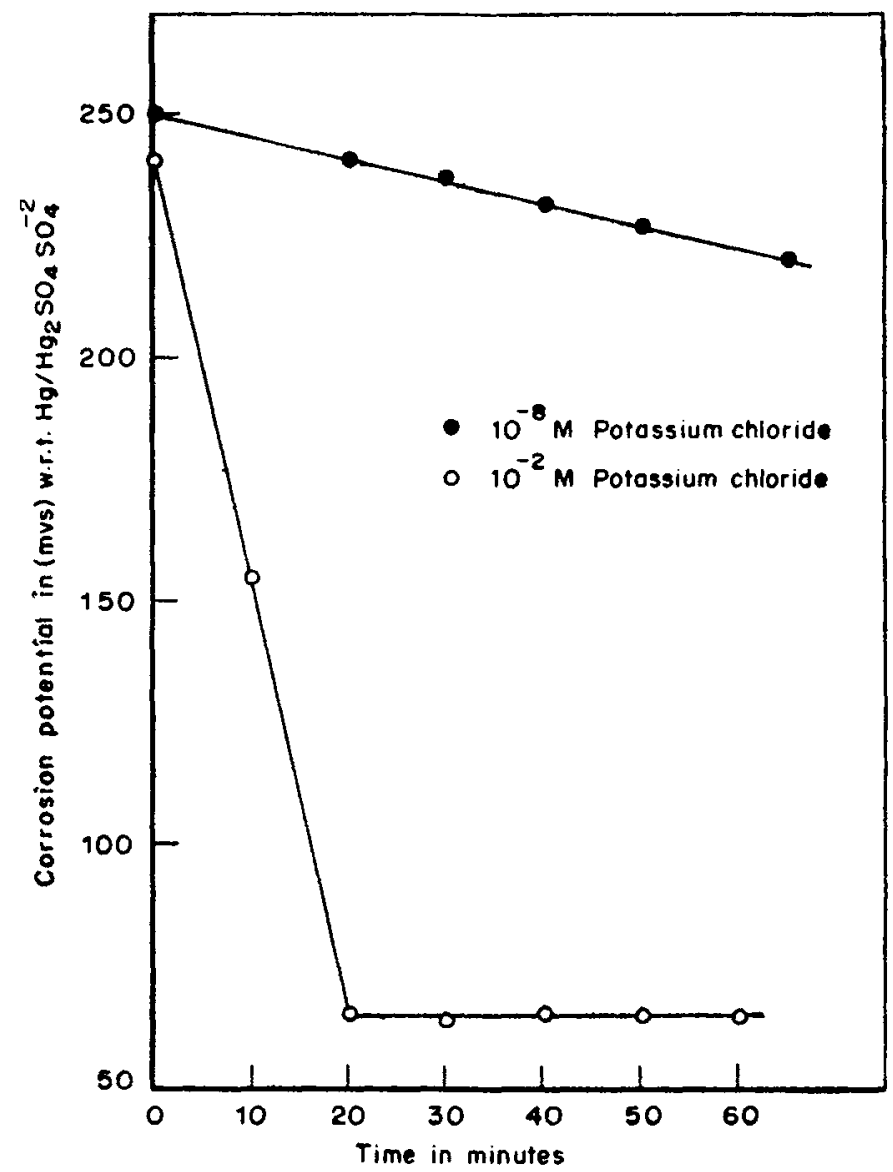

Figure 3. Variation of corrosion potential of copper (110) face with time in $0.1 \mathrm{~N}$ sulphuric acid containing $10^{-8} \mathrm{M}$ and $10^{-2} \mathrm{M} \mathrm{Cl}^{-}$ions. 


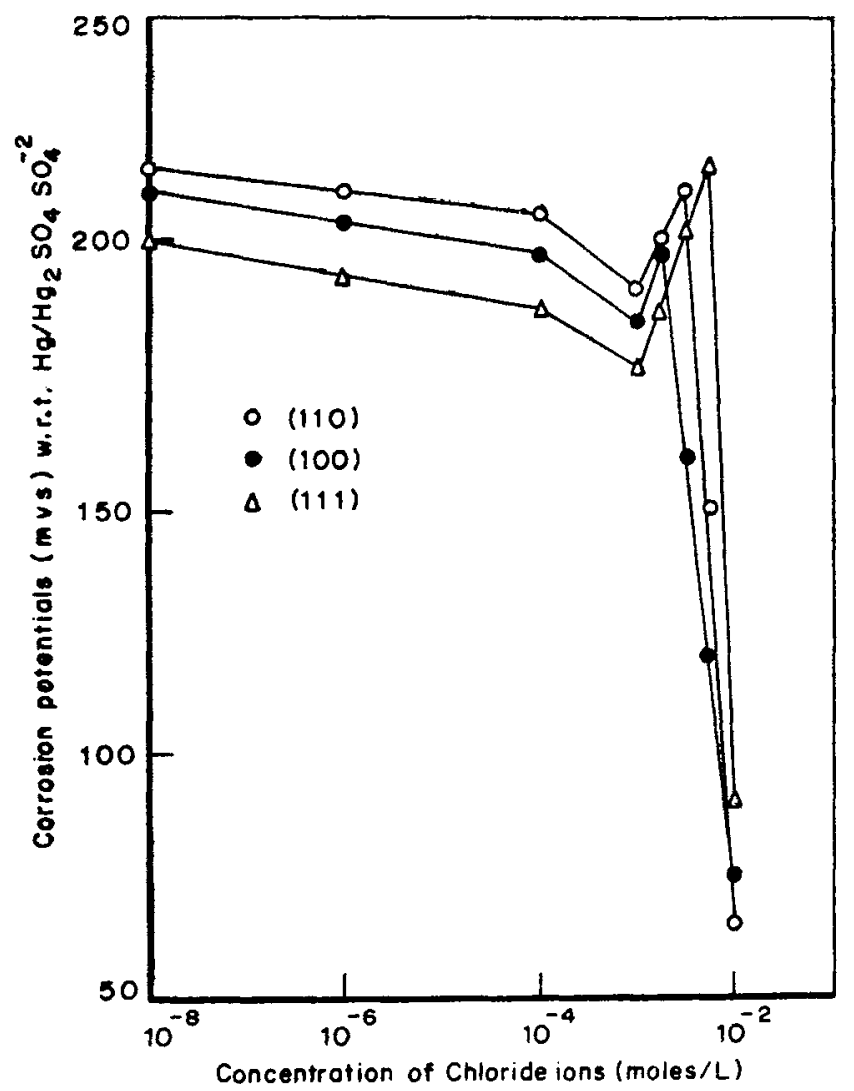

Figure 4. Influence of $\mathrm{Cl}^{-}$ion concentration $(C$, mole/l) on corrosion potentials of copper single crystal faces at $30^{\circ} \mathrm{C}$.

The corrosion potentials of the crystal faces decreased without attaining steady values up to $7.5 \times 10^{-3} \mathrm{M} \mathrm{Cl}$ ions. However, corrosion potential attained steady value at $10^{-2} \mathrm{M} \mathrm{Cl}^{-}$ions. Up to $7 \cdot 5 \times 10^{-3} \mathrm{M} \mathrm{Cl}^{-}$ions, initial corrosion potentials of the crystal faces were not a function of $\mathrm{Cl}^{-}$ion concentration and crystallographic orientation but at $10^{-2} \mathrm{M} \mathrm{Cl}^{-}$ions, initial corrosion potentials were in the order $(111)>(100)>(110)$. The final corrosion potentials of the crystal faces varied with $\mathrm{Cl}^{-}$ion concentration and crystallographic orientation (figure 4). These potentials were in the order $(110)>(100)>(111)$ up to $7.5 \times 10^{-3} \mathrm{M} \mathrm{Cl}^{-}$ions, but this order changed to $(111)>(100)>(110)$ in presence of $10^{-2} \mathrm{M} \mathrm{Cl}^{-}$ions.

\section{Discussion}

Halide ions are known to adsorb strongly even in traces on the surface ${ }^{14}$ (preferentially at the Inner Helmholtz plane of the double layer). This 
changes the structure of the double layer. The dissolved oxygen has significant effect on the corrosion of copper ${ }^{15},{ }^{16}$. Oxygen at the interface is more important than in the bulk of the solution. The change in the structure of the double layer hinders the inflow of oxygen at the interface. Hence we could expect a slightly lower corrosion rate in presence of traces $\left(\sim 10^{-8}\right.$ $M$ ) of $\mathrm{Cl}^{-}$ions than the corrosion rate in $0.1 \mathrm{~N}$ sulphuric acid. The corrosion process is controlled by the surface reaction since the energy of activation for the corrosion process is greater than $5 \mathrm{kcals}$ (table 2). The negative entropy of activation may be due to the increase in the rigidity of the normal reactant material when it passes from normal state to activated state during corrosion reaction.

Since the corrosion rate is being affected by the presence of $\mathrm{Cl}^{-}$ions, the following mechanism could be written in the light of the earlier experimental facts. ${ }^{7,}$ 16-19

$$
\begin{aligned}
& \text { 1. } 2 \mathrm{Cu}+4 \mathrm{Cl}^{-} \rightleftharpoons 2 \mathrm{CuCl}_{2}^{-}+2 \mathrm{e} \\
& \text { 2a. } 2 \mathrm{CuCl}_{2} \rightleftharpoons 2 \mathrm{Cu}^{+}+4 \mathrm{Cl}^{-} \\
& \text {2b. } 2 \mathrm{CuCl}_{2} \rightleftharpoons 2 \mathrm{CuCl}^{2}+2 \mathrm{Cl}^{-} \\
& \text {3. } 2 \mathrm{Cu}^{+}+\mathrm{O}_{2}+4 \mathrm{H}^{+}+2 \mathrm{e} \rightarrow 2 \mathrm{Cu}^{2+}+2 \mathrm{H}_{2} \mathrm{O} .
\end{aligned}
$$

The $\mathrm{Cl}^{-}$ions get adsorbed at the active sites on the surface and form a complex ${ }^{17,18}$ (step 1). The $\mathrm{CuCl}_{2}-$ formed, dissociate to give $\mathrm{Cu}^{+}$ions (step $2 a$ ) which may accumulate in the diffusion layer. The oxygen which diffuses on to the surface gets depolarised by the electrons released and simultaneously $\mathrm{Cu}^{+}$ions get oxidized ${ }^{19}$ to $\mathrm{Cu}^{2+}$ ions (step 3) at a distance $(\delta-a)$ from the electrode surface, ${ }^{16}$ where " $\delta$ " is the thickness of the diffusion layer and " $a$ " is the part of the thickness of the diffusion layer through which oxygen diffuses towards the surface. Hydorchloric acid which is formed from the chloride increases the corrosion rate since its degree of ionization is much higher than that of sulphuric acid and it is reasonable for the corrosion rate to increase with increased availability of $\mathrm{Cl}^{-}$ions. Thus the complex formation itself sets in above $10^{-3} \mathrm{M} \mathrm{Cl}^{-}$ions and accounting for the sudden increase in corrosion rate. When more chloride is added the solubility product of the complex (cuprous chloride) is reached; it deposits in the form of a thin film ${ }^{7}$ (step $2 b$ ) and brings down the corrosion by progressively lowering the surface. Hence $\mathrm{Cl}^{-}$ions act as corrosion stimulator at low concentrations and corrosion inhibitor at high concentrations. This is in agreement with the views of Brasher. ${ }^{6}$

In practice ${ }^{20}$ it is more probable to expect a non-uniform porous film on the metal surface and hence $100 \%$ inhibition may not be possible in presence 
of $10^{-2} \mathrm{M} \mathrm{Cl}^{-}$ions. If there is no film on the surface, we would have got a linear relation between weight loss and time as in pure dilute sulphuric acid (figure 2). When crystal dissolves in acid, surface becomes faceted. ${ }^{12,}{ }^{21}$ The faceting is not observed under these conditions, perhaps there may be a hindrance to the flow of steps on the surface by the film ${ }^{20}$ and hence we could expect the existence of a film on the surface of the crystal face.

At high concentration $\left(10^{-2} M\right)$, passivity sets in and hence we could expect steady corrosion potential (figure 3). Corrosion potentials become less noble at high concentration of $\mathrm{Cl}^{-}$ions with reference to corrosion potentials in sulphuric acid. This indicates the inhibition of cathodic reaction ${ }^{22}$ of the corrosion process by $\mathrm{Cl}^{-}$ions.

\section{ACKNOWLEDGEMENT}

One of the authors (S. M. M.) is indebted to Prof. T. P. Hoar, Cambridge University, England, for constructive criticism.

\section{REFERENCES}

1. Evans, U. R., The Corrosion and Oxidation of Metals (Arnold, London) p. 139 (1960).

2. De, C. P., Nature (London) 1811060 (1958).

3. Pryor, M. J., Z. Electrochem. 62782 (1958).

4. Piontelli, R., Z. Electrochem. 55128 (1958).

5. Gortledge, G. H., J. Phys. Chem. 6032 (1952).

6. Brasher, D. M., Nature (London) 193868 (1962).

7. Hurlen, T., Acta Chem. Scand. 151246 (1961).

8. Bertocci, U., J. Electrochem. Soc. 113604 (1966).

9. Beeck, O., Smith, A. E. and Wheeler, A., Proc. Roy. Soc. (London) 177A 62 (1940).

10. Sherman, A. and Eyring, H., J. Amer. Chem. Soc. 542661 (1932).

11. Jacquet, P. A., Metal Rev. 1157 (1956).

12. Mayanna, S. M. and Setty, T. H. V., Indian J. Chem. 10295 (1972).

13. Laidler, K. J., Reaction Kinetics (Pergamon Press, London) 185 (1963).

14. Bockris, J. O'M., Devanathan, M. A. V. and Muller, K., Proc. Roy. Soc. (London) 274 A 55 (1963).

15. Russel, R. P. and White, A., J. Ind. Engng. Chem. 19116 (1927). 
16. Bertocci, U., Electrochim. Metal. 3 (3) 227 (1968).

17. Kolotyrkin, J. M., J. Electrochem. Soc. 108209 (1961).

18. Bjerrum, J., Schwarzenbach, G. and Sillen, L. G., Stability Constants, Part HH (The Chemical Society, London) (1958).

19. Jenkins, L. H., J. Electrochem. Soc. 11375 (1966).

20. Vermilyea, D. A., Advances in Electrochemistry and Electrochemical Engineering, eds Paul Delahay and Tobias, C. W. (Interscience Publishers, New York) 3211 (1963).

21. Frank, F. C., Growth and Perfection of Crystals, eds Doremus, R. H., Roberts, B. W. and Turnbull, D. (Wiley, New York) p. 411 (1958).

22. Hoar, T. P. and Holliday, R. D., J. Appl. Chem. 3502 (1953). 